
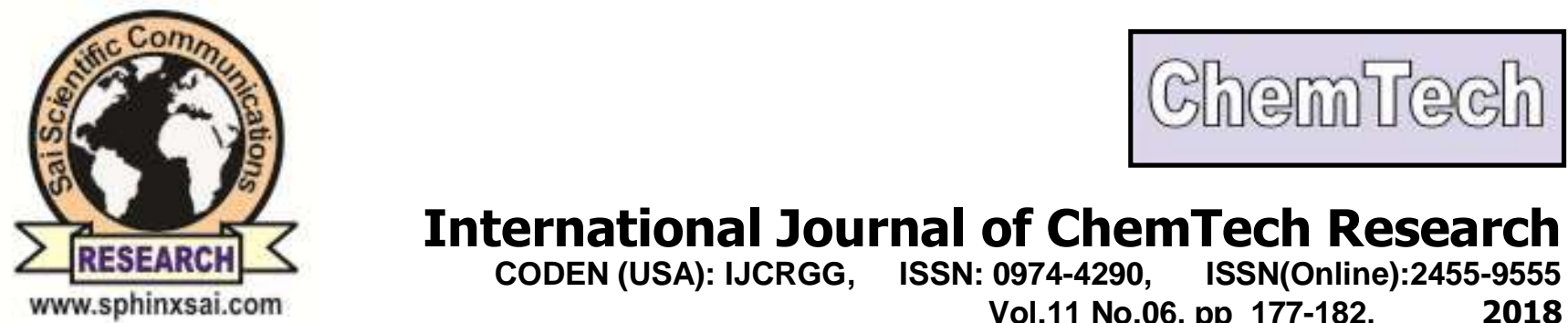

International Journal of ChemTech Research

CODEN (USA): IJCRGG, ISSN: 0974-4290, ISSN(Online):2455-9555

\title{
Caffeine increases PGE2 levels at compression and tension areas during orthodontic tooth movement
}

\author{
Herniyati $^{1 \star}$, Ida Bagus Narmada ${ }^{2}$, Leliana Sandra Devi ${ }^{3}$ \\ ${ }^{1}$.Department of Orthodontic, Faculty of Dentistry, University of Jember, Jember, \\ Indonesia. \\ 2. Head, Department of Orthodontic, Faculty of Dentistry, Airlangga University, \\ Surabaya, Indonesia \\ 3. Department of Orthodontic, Faculty of Dentistry, University of Jember, Jember, \\ Indonesia
}

\begin{abstract}
Objective: To analyze the effect of caffeine on PGE2 levels during orthodontic tooth movement. Experimental: Sixteen healthy male rats were divided into two groups, i.e. control group $(\mathrm{C})$ consisted of eight rats applied with orthodontic force $(\mathrm{OF})$, and treatment group (T) consisted of eight rats applied with OF and caffeine $1.35 \mathrm{mg} / 100 \mathrm{~g} \mathrm{BW}$ twice a day for 14 days. The rats were anesthetized using ketamine, and subsequently OF was applied. A ligature wire with a diameter of $0.20 \mathrm{~mm}$ was mounted by attaching on the maxillary right first molar and both of the maxillary incisors. Next, the maxillary right first molar was moved to mesial using a tension gauge to generate $10 \mathrm{~g} / \mathrm{cm} 2$ by using nickel titanium orthodontic closed coil spring. The observations were carried out on the $8^{\text {th }}$ and $15^{\text {th }}$ days of study period, GCFs were taken by placing the paper points in the gingival sulcus of mesio-and disto-palatal permanent maxillary right first molar. PGE2 levels was determined by using ELISA. Results: caffeine on $8^{\text {th }}$ and $15^{\text {th }}$ days enhanced PGE2 levels on the compression and tension areas ( $p$ $<0.05)$. PGE2 levels on the compression area were significantly greater compared to that in the tension area ( $\mathrm{p}<0.05)$. Conclusion: Caffeine increased PGE2 levels during orthodontic tooth movement. Caffein can trigger osteoclast formation and increase the efficiency of tooth movement, thus it may enhance the effectiveness of orthodontic treatment in the future.

Keywords : Orthodontic tooth movement, caffein, PGE2 , GCF.
\end{abstract}

\section{Introduction}

The movement of teeth occurs as a direct result of tissue remodeling around the tooth root because of the applied force. Remodelling requires cells that may resorb and forms extracellular matrix of periodontal ligament and alveolar bone. When orthodontic force is applied, the periodontal ligament will narrow on the compression area followed by resorption of alveolar bone due to osteoclast activity. In contrast, bone resorption caused by osteoblasts occurs on tension area ${ }^{1}$.

Herniyati et al /International Journal of ChemTech Research, 2018,11(06): 177-182.

DOI= http://dx.doi.org/10.20902/IJCTR.2018.110622 
The movement of teeth that occurs as a result of orthodontic force applications leads to an inflammatory process. The inflammatory process that occurs consists of degranulation of intracellular granules icreases vascular permeability, degenerative and reformative changes in periodontal ligaments, synthesis and prostaglandin secretion, followed by bone remodeling ${ }^{2}$.

Prostaglandin (PG) is a group of chemical messengers belonging to a family of hormones called eicosanoids. They are paracrine hormones that work only on cells near the synthesis point of hormones instead of transporting blood to work on cells in tissues or other organs, and they have potential effects on vertebrate tissue, all eicosanoids are originated from arachidonic acid, from which they take their common name (eikosi in Greek means twenty) ${ }^{3}$.

PG, especially PGE2, acts as an inhibitor or stimulator in the metabolism of bone, depending on the physiological or pathological conditions. The effect of anabolic occurs primarily as a bone response to application of mechanical force and to the healing of bone fractures, whereas PGE2-mediated bone resorption increases bone loss in inflammatory diseases and in response to prolonged immobilization ${ }^{4,5,6}$. PGE2 is a strong bone resorption stimulator by enhancing the replication and differentiation of osteoclast precursors ${ }^{7}$.

In the movement of orthodontic tooth PGE2 may become a mediator of mechanical stress. PGE2 stimulates bone resorption, root resorption, reduces collagen synthesis, and increases cAMP. PGE2 stimulates bone resorption by enhancing the osteoclasts number and activating osteoclasts. The results show that low PGE2 concentrations $(0.1 \mu \mathrm{g})$ were effective in increasing orthodontic tooth movement, whereas higher concentrations caused root resorption. Systemic delivery has been reported to have a better effect compared to local administration ${ }^{8}$.

Various molecules are capable of passing through the sulcular gingival epithelium and entering into Gingival crevicular fluid (GCF). Most of these molecules are related to the remodeling of the nucleus tissue during conditions like normal treatment, periodontal disease and orthodontic treatment. GCF collection is a non-invasive procedure, which provides periodontal and orthodontic diagnostic information regarding to the nature and level of periodontal health or disease, and patient response to mechanotherapy ${ }^{9}$. The evidence suggests that a crevicular fluid analysis is a useful method for assessing cellular response to orthodontic forces in vivo. The study has been conducted to determine levels and PGE2 in GCF of young adult patients by continuous-force canine retraction with nickel-titanium coil springs and adjacent teeth receiving intermittent force with an embedded retractor; the force is reactivated every week with 2 turns of the screw. The results show that in groups receiving continuous forces PGE2 levels indicated significant elevation in $24 \mathrm{~h}$ and afterward decreased. For groups which received intermittent force PGE2 levels increased significantly in $24 \mathrm{~h}$ and remained high for 1 week ${ }^{10}$.

Caffeine is the most commonly used pharmacological active substance in the world, found in coffee and tea drinks, cocoa products, and some drugs. Consumption of high energy drinks containing high caffeine has enhanced significantly in recent years ${ }^{11}$. The results show that $0.01 \mathrm{mM}$ of caffeine significantly increases PGE2 production in vitro on media from the periodontal ligament ${ }^{12}$.

This study was conducted to analyze the effects of caffeine on PGE2 levels during orthodontic tooth movement using rats as animal research. It is expected that this research can be successfull to be used as a therapy to accelerate bone remodeling and to shorten the orthodontic treatment time, to minimize the side effects, to be easy to obtain and relatively economical.

\section{Experimental}

Sixteen healthy male rats (Spraque Dauwley) 250-300 grams, 3 to 4 months were divided into two groups, 8 rats each group i.e. control group (C) was applied with orthodontic force $(\mathrm{OF})$ and treatment group (T) was applied with OF and caffeine (TCI-American- United States) of $1.35 \mathrm{mg} / 100 \mathrm{~g}$ BW dissolved in $2 \mathrm{ml}$ distilled water. Caffeine was administered orally twice a day, in the morning and in the afternoon using stomach probe for 14 days.

Subsequently the rats were anesthetized using ketamine, and applied using OMF. A ligature wire (3 M Unitek, Germany) with a diameter of $0.20 \mathrm{~mm}$ was mounted by attaching on the maxillary right first molar and both of the maxillary incisors. The maxillary right first molar was moved to mesial using a tension gauge (Ormco, USA) to generate $10 \mathrm{~g} / \mathrm{cm}^{2}$ strength with nickel titanium orthodontic closed coil spring (3M, Unitek Germany) sized $6 \mathrm{~mm}$ long $^{13}$. The observations were carried out on the days 8 and 15 to take the GCF by 
placing the paper points to gingival sulcus of mesio-palatal and disto-palatal of permanent maxillary right first molar for 30 seconds and stored in eppendorf tubes ${ }^{14}$. Determination of PGE2 levels was performed by ELISA method (CusaBio, USA).

The installation of closed coil spring from maxillary right first molar to the both of the maxillary incisors in rats is shown in FIG. 1 and the taking of GCF of the gingival sulcus of mesio-palatal and palatal distal maxillary right first molar is shown in FIG. 2

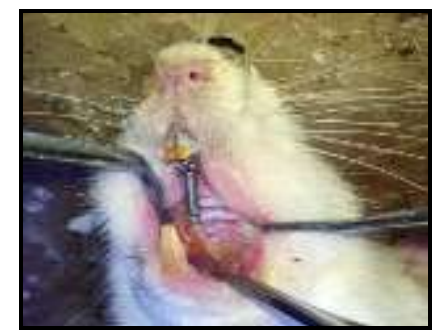

Figure 1. Installation of closed coil spring on the rat.

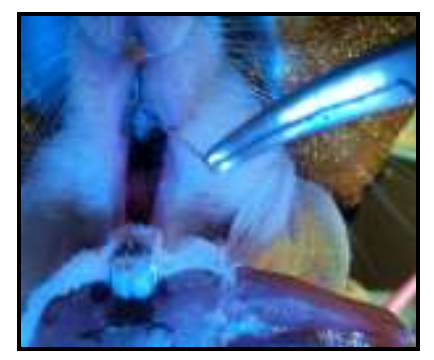

Figure 2. The GFC taking on gingival sulcus on the rat.

The statistical analysis was conducted using independent test, paired t-test, Mann Whitney test and Wilcoxon Signed Ranks test with 95\% level of significance $(\alpha=0,05)$. This study has been approved by the Ethical Research Committee of the Dental Faculty, Airlangga University, Number: 18/KKEPK.FKG/II/2015

\section{Results}

The study showed that PGE2 levels on day $8^{\text {th }}$ on the compression area and on the tension area in the T group were significantly greater compared to those in the $\mathrm{C}$ group $(\mathrm{p}<0.05)$. In the $\mathrm{C}$ group PGE2 levels in the compression area were greater compared to those in the tension area but not significant ( $p>0.05)$, whereas in the T group the PGE2 levels on the compression area were significantly greater compared to those on the tension area $(\mathrm{p}<0.05)$ (Table 1$)$.

The PGE2 levels on the day $15^{\text {th }}$ on the compression area and on the tension area in the $\mathrm{T}$ group were significantly greater compared to those in the $\mathrm{C}$ group $(\mathrm{p}<0.05)$. Both the $\mathrm{C}$ group and the $\mathrm{T}$ group showed PGE2 levels on the compression area were significantly greater compared to those in the tension area $(\mathrm{p}<0.05)$ (Table 1).

Table 1. PGE2 levels and Difference Test among Research Groups on the Compression Area and Tension Area.

\begin{tabular}{|c|c|c|c|c|c|c|c|}
\hline \multirow{3}{*}{ Groups } & \multirow{3}{*}{$\mathbf{n}$} & \multicolumn{6}{|c|}{ PGE2 (pg/ml) (Mean \pm Standard Deviation) } \\
\hline & & \multicolumn{3}{|c|}{ Day-8 } & \multicolumn{3}{|c|}{ Day-15 } \\
\hline & & Compression & Tension & p & Compression & Tension & p \\
\hline C & 5 & $2,71 \pm 0,68$ & $1,91 \pm 0,80$ & 0,077 & $2,570 \pm 0,76$ & $1,87 \pm 0,23$ & 0,010 \\
\hline $\mathbf{T}$ & 5 & $7,11 \pm 0,66$ & $3,15 \pm 0,59$ & 0,000 & $7,96 \pm 0,33$ & $2,75 \pm 0,30$ & 0,000 \\
\hline $\mathbf{p}$ & & 0,000 & 0,000 & & 0,000 & 0,016 & \\
\hline
\end{tabular}

Notes :

$\mathrm{p}<0,05=$ significantly different

$\mathrm{p}>0,05=$ not significantly different 
Table 2 PGE2 Levels and Differrence Test between Day 8 and Day 15 on Each Research Group

\begin{tabular}{|l|l|l|c|c|c|c|l|}
\hline \multirow{2}{*}{ Groups } & \multirow{2}{*}{$\mathbf{n}$} & \multicolumn{6}{|c|}{ PGE2 (pg/ml) } \\
\cline { 3 - 8 } & & Day-8 & Day-15 & p & Day-8 & Day-15 & p \\
\hline C & 5 & $2,71 \pm 0,68$ & $2,570 \pm 0,76$ & 0,182 & $1,91 \pm 0,80$ & $1,87 \pm 0,23$ & 0,701 \\
\hline T & 5 & $7,11 \pm 0,66$ & $7,96 \pm 0,33$ & 0,090 & $3,15 \pm 0,59$ & $2,75 \pm 0,30$ & 0,138 \\
\hline
\end{tabular}

Notes :

$\mathrm{p}<0,05=$ significantly different

$\mathrm{p}>0,05=$ not significantly different

In the T group on the compression area and on the tension area there was a decrease in PGE2 on the day $15^{\text {th }}$ compared to the day $8^{\text {th }}$ but not significant ( $\mathrm{p}>0.05$ ), whereas in the T group on the compression area PGE2 increased but not significant ( $p>0.05$ ), whereas on the tension area the PGE2 levels decreased ( $>$ > 0.05) (Table 2).

\section{Discussion}

The mechanical orthodontic force which is applied to the tooth will lead to a series of events initiated by mechanical deformation of cells and extracellular matrix. Bone deformation, periodontal ligament compression, and tissue trauma lead to release of some extracellular molecules carrying signals, called first messengers, including parathyroid hormones, neurotransmitters and prostaglandins. Cell-shape changes will lead to the release of arachidonic acid from the cell surface leading to the release of prostaglandins and leukotrin via the cyclo-oxygenase pathway as well as the lipo-oxygenase pathway. The first messenger will bind to the receptor of the target cell and initiate the intracellular signaling process. This stimulates the release of the second messenger, including cAMP, cGMP, and intracellular calcium. The formation of a second messenger inside the cell is believed to initiate the formation of bone cells. In addition through the establishment of the first and second messenger, there are alternate biological pathways for orthodontic tooth movement. Orthodontic force also causes tissue trauma in certain amount. Subsequently, the hydrolytic enzyme will be released which will activate the collagenase enzyme causing bone resorption ${ }^{15,1}$.

Caffeine administration increases levels of PGE2 on the compression area and the tension area compared to that not caffeine administration with on the day 8. This is consistent with the results of in vitro studies demonstrating that $0.01 \mathrm{mM}$ of caffeine significantly increases PGE2 production on media from the periodontal ligament, which is supported also with the results of in vivo research showing that caffeine significantly improves orthodontic tooth movement through increased RANKL and osteoclastogenesis (8). Previous research has also shown that low concentrations of caffeine lead to increased RANKL reinforced by COX2 / PGE2 in osteoblasts, resulting in increased osteoclast formation ${ }^{16}$.

In orthodontic tooth movement caffeine works in two ways: increasing intracellular cAMP concentrations, and mediators regulating inhibition of osteoblast proliferation, first caffeine inhibits phosphodiesterase that breaks cAMP; second caffeine induces increased release of prostaglandin E 2 (PGE 2) in vitro and in vivo. The high concentrations of PGE2 may increase intracellular cAMP in osteoblasts and has also been reported to increase osteoclast activity (and inhibit collagen synthesis, leading to faster bone resorption and slower bone deposition ${ }^{17}$.

The orthodontic tooth movement is a complex process involving many factors. The applied orthodontic force will cause tissue trauma, periodontal ligament compression, and bone deformation. Furthermore, it will occur signal transduction i.e. a change from mechanical force into form of molecular event. Prostaglandins are involved in the signal transduction. The mechanical deformation occurring in periodontal ligament cells will lead to the release of the first messenger, including prostaglandins. The first messenger will then stimulate a second messenger release, including cAMP and intracellular calcium, which will then activate the osteoclast. In addition, prostaglandins binding to EP4 receptors on the surface of osteoblasts will trigger the formation of RANKL, if bound to RANK present on the surface of osteoclast progenitor cells, will activates osteoclasts to resorb bone, and some researchers have proved that prostaglandin administration may accelerate almost two fold of orthodontic tooth movement ${ }^{18}$. 
Caffeine administration increases PGE2 levels on the compression area more than that in the tension area because the role of PGE2 on the compression area is required more for osteoclastogenesis than that on the tension area as a result bone resorption increases. The results of previous studies also show that caffeine increases RANKL and osteoclastogenesis more on the compression area than that the tension area ${ }^{19}$.

On the day $15^{\text {th }}$ in the control group there was a slight but insignificant decrease. It is consistent with the results of the study of Grieve $e a^{20}$, which shows that IL-1 $\beta$ and PGE2 are increased significantly after the initial tooth movement then returned to baseline after seven days. Other results also show PGE2 levels increase significantly in $24 \mathrm{~h}$ and remain high for 1 week $^{10}$. In the treatment group there is an increase, although not significant, indicating that caffeine administration increases PGE2.

The conclusion is that caffeine effectively increases PGE2 levels. PGE2 acts as a trigger for the formation of RANKL in osteoblasts and afterward enhances the osteoclasts number and orthodontic tooth movement.

\section{References}

1. Cardaropoli D. and Gaveglio L., The influence of orthodontic movement on periodontal tissues level, Semin Orthod., 2007,13, 234-45.

2. Nanda R., Biomechanics and esthetic strategies in clinical orthodontics, St. Louis: Elsevier Saunders, 2005, 17-27.

3. Nelson D. and Cox M., Lehninger's Principles of Biochemistry, 4th ed., New York: W.H. Freeman and Co, 2004, 358.

4. Pilbeam CC, Harrison JR, Raisz LG.,Prostaglandin and bone metabolism. In: Bilezikian JP, Raisz LG, Rodan GA (Ed).Principles of bone biology, San Diego:American Press Inc, 1996, 715-22.

5. Fracon RN, Teofilo JM, Satin RB, Lamano T., Prostaglandins and bone: Potential risks andbenefits related to the use of nonsteroidal anti-inflammatory drugs in clinical dentistry, J Oral Sci., 2008, 50, 247-52.

6. Yamasaki K, Shibata Y, Imai S, Tani Y, Shibasaki Y, Fukuhara T., Clinical applicationof prostaglandin E1 upon orthodontic toothmovement, Am J Orthod., 1984, 85, 508-18.

7. Machwate M, Harada S, Leu CT, et al., Prostaglandin receptor EP4 mediates the boneanabolic effects of PGE2, Mol Pharmacol., 2001, 60, 36-41.

8. Diravidami K, Sivalingam SK, and Agarwal V. Drugs influencing orthodontic tooth movement: An overall review. Dental Science - review article 2012;4(6):299-303

9. Patil AK, Shetty AS, Setty S, Thakur S., Understanding the advances in biology of orthodontic tooth movement for improved ortho-perio interdisciplinary approach, J Indian Soc Periodontol., 2013, 17(3), 309-318

10. Lee KJ, Park YC, Yu HS, Choi SH, Yoo YJ., Effects of continuous and interrupted orthodontic force on interleukin-1beta and prostaglandin E2 production in gingival crevicular fluid, Am J Orthod Dentofacial Orthop., 2004, 125,168-77.

11. Reissig CJ, Strain EC, Griffiths RR., Caffeinated energy drinks - A growing problem. Drug Alcohol Depend., 2009, 99,1-10.

12. Yi, Yan B, Li M, Wang Y, Zheng W, Li Y, Zhao Z., Caffeine may enhance orthodontic tooth movement through increasing osteoclastogenesis induced by periodontal ligament cells under compression. Archives of Oral Biology 2016, 64, 51-60

13. D'Apuzzo F, Cappablanca S, and Clavarella D, Monsurrò A, Biavati S, Perillo L., Biomarkers of periodontal tissue remodelling during orthodontic tooth movement in mice and men: overview and clinical relevance, Sci World J., 2013, 41, 342-53.

14. Zia A, S Khan, A Bey, ND Gupta, S Mukhtar-UN., Oral Biomarker in the diagnosis and progression of periodontal diseases, Biology and Medicine, 2011, 3(2), 45-52.

15. Bhalajhi SI., Orthodontics: The a rt and science. $3^{\text {rd }}$ ed., New Delhi: Arya (MEDI) Publishing House, 2006, 181-94.

16. Liu SH, Chen C, Yang RS, Yuan PYen, Yang YT,Tsai C., Caffeine enhances osteoclast differentiation from bone marrow hematopoietic cells and reduces bone mineral density in growing rats, Journal of Orthopaedic Research, 2011, 29(6), 954-960.

17. Yi J, Zhang L, Yan B, Yang L, Li Y, Zhao Z., Drinking coffee may help accelerate orthodontic tooth movement, Original Hypotheses, 201, 3(2), 72-75. 
18. Iskandar P. and Ismaniati NA., Peran prostaglandin pada pergerakan gigi ortodontik, Dentofasial, 2010 ,9(2),91-100

19. Herniyati, Mekanisme pergerakan gigi ortodonti dan proses remodeling tulang alveolar yang diinduksi gaya mekanis ortodonti akibat pemberian seduhan kopi. Dissertation. Surabaya: Program Studi Ilmu Kedokteran Jenjang Doktor, Fakultas Kedokteran Universitas Airlangga, 2016, 99-101.

20. Grieve WG, Johnson GK, Moore RN, Reinhardt RA, Dubois LM., Prostaglandin E (PGE) and interleukin-1 $\beta$ (IL-1 $\beta$ ) levels in gingival crevicular fluid during human orthodontic tooth movement, Am J Orthod Dentofacial Orthop., 1994,105 (4), 369-374. 